\title{
Different but the Same: Doctoral Students' Experience of Multiprofessional Education
}

\author{
Hilary Piercy ${ }^{*}$, Frances Gordon \\ Sheffield Hallam University, Centre for Health and Social Care Research, 32 Collegiate Crescent, Sheffield, UK \\ *Corresponding author: h.piercy@shu.ac.uk
}

Received February 12, 2015; Revised March 01, 2015; Accepted March 16, 2015

\begin{abstract}
Generic Professional Doctorate programmes provide students with the opportunity to study in multiprofessional cohorts. Although the professional doctorate student experience has been examined, the value of engaging in multiprofessional doctoral education has not been explored. The study aimed to explore the personal meanings that doctoral students ascribe to the value of studying within a multiprofessional context. A qualitative approach was employed. Data were collected through focus group discussions and individual interviews. A thematic analysis was conducted on the data. 23 doctoral students over four years of the programme participated in the study. Different but the same was a major theme that emerged from the data. The multiprofessional context and the 'difference' between the students offered identifiable enhancements to the academic process which were captured in three subthemes; 1) finding new worlds 2) getting clear and being clear and 3) travelling alone together. The study findings suggest that the multiprofessional context, mediated through a pedagogical approach of the contact hypothesis, enhanced the quality of the educational experience and outcomes.
\end{abstract}

Keywords: professional doctorate, multiprofessional, cohort, qualitative method, education

Cite This Article: Hilary Piercy, and Frances Gordon, "Different but the Same: Doctoral Students' Experience of Multiprofessional Education.” American Journal of Educational Research, vol. 3, no. 4 (2015): 393-398. doi: 10.12691/education-3-4-2.

\section{Introduction}

This study concerns a Professional Doctorate programme in a University in the Midlands region of England. It is accessed by students working across a range of sectors concerned with health and wellbeing. Professional Doctorates are defined by the United Kingdom Council for Graduate Education as programmes of advanced study and research that satisfy the criteria for the award of a doctorate but are designed to meet the needs of professional groups in the wider workplace [1].

Professional doctorate programmes, as we currently understand them, were developed in single professional disciplines and centred primarily on the professions of education, engineering and psychology. Since the introduction of the first Doctorate in Education in the USA in the early $20^{\text {th }}$ century, provision has steadily expanded across the anglophone countries. Over the last twenty years, an increasing number of academic institutions in Australia, USA, Canada and the UK have offered this qualification. Expansion of provision has been characterised by a move to include more generic approaches [2]. This can be attributed to a recognition of thevalue of doctoral qualifications to a wide range of professions and a realisation that there are viability problems associated with sustaining viable cohorts of single professions [3]. The development of 'generic' professional doctorates is seen as a solution to the viability issue [4]. Arguably therefore the primary drivers for generic professional doctorates in the UK were instrumental and financial. The premise of this paper however, is that the generic professional doctorate in a multiprofessional context provides enhancement to the learning experience and outcomes of students.

Our programme is a generic programme offered as a faculty-wide provision and recruiting students across the areas of Health, Social Care, Sport and Biomedicine. The educational delivery model is as follows: an annual intake of a cohort of up to 15 students who access a structured programme of four taught modules over the first two years followed by an independent research project. This differs from the traditional $\mathrm{PhD}$ structure in the UK but may mirror models of PhDs provided internationally. Cohorts are diverse and include students from social work; public health; the allied health professions, social marketing; nursing; medicine; sports science and biomedical science.Students share a common overarching professional identify of Health and Wellbeing. This offers a potentially rich learning environment and a context in which to examine the degree to which multiprofessional learning contributes to the academic development of students undertaking doctoral study.

Multiprofessional education has been defined as 'occasions when two or more professions learn side by side for whatever reason' [5]. This 'multiprofessional' approach can be distinguished from 'interprofessional education' that occurs "when two or more professions learn with, from and about each other to improve 
collaboration and the quality of care" [5]. Collaborative practice in health and social care is an international issue. The World Health Organisation acknowledge that collaborative practice is key to improving health outcomes globally and the achievement of the health related Millennium Development Goals [6].

Whilst we do not claim an interprofessional pedagogy and collaborative outcomes are not explicit aims of our Programme, its location within an institutional environment that supports the UK imperative of interprofessional learning and working $[7,8,9]$ gives rise to questions regarding the extent to which collaborative outcomes within the context of multiprofessional education at doctoral education might be realised and how this may contribute to the learning experience.

A growing body of work has examined the professional doctorate in terms of: student experience, the value of the cohort experience, and impact on professional practice (e.g. 10,11). However, the student experience of engaging in multiprofessional doctoral education does not appear to have been articulated.

The study aim was therefore to explore the personal meanings that doctoral students ascribe to the value of studying within a multiprofessional context.

\section{Method}

The study approach was situated within a social constructionist theoretical perspective and is located, therefore, in a qualitative paradigm [12].

Data were generated through a mix of focus group discussions and individual interviews with students across four years of the programme. All data collection followed a semi structured approach and used a topic guide with key questions and a series of probes that collectively addressed the overall aim of the study. All interviews were recorded and fully transcribed. They were anonymised at the point of transcription. Verbal consent from all participants was obtained and recorded.

A purposive sampling approach was adopted to ensure diverse and comprehensive representation of students across all stages of the programme and all professional groups. A total of four focus groups were conducted with 3-10 students in each. Each focus group was facilitated by two researchers to ensure the quality of data collection. Additionally, to ensure maximum representation across cohorts, individual interviews were conducted with two students in the research phase of the programme who were unavailable to attend a focus group. A total of 23 students participated in the project (see Table 1 for details).

A thematic analysis was conducted on the data. Thematic analysis is described by Braun and Clark as a "method for identifying, analysing and reporting patterns (themes) within data" [13]. Our theoretical approach, whilst situated in a social constructionist perspective, could be argued as being hybrid [14]. The inductive element to our analysis reflects our overall data driven approach to identifying themes and sub-themes [15]. However this was informed by a deductive approach in so far as coding decisions were theory driven by our interest in the multiprofessional aspects of the students' experience [16]. Analysis followed the four stages recommended by Braun and Clark [13]. Both researchers (HP\&FG) were involved in the analysis process to ensure the rigour of the process. They coded the data individually and then compared these to refine the analysisand agree a thematic framework.

Table 1. Overview of the participants

\begin{tabular}{|l|l|l|}
\hline Year of programme & Professional groups & Numbers \\
\hline 1 & Nurse (N) & 2 \\
\hline & Therapy Radiographer (RT) & 1 \\
\hline & Biomedical scientist (BS) & 2 \\
\hline & Social marketing specialist (SMS) & 1 \\
\hline & Diagnostic radiographer (DR) & 1 \\
\hline & NHS manager (M) & 1 \\
\hline 2 & Anaesthetic practitioner (AP) & 1 \\
\hline & Social worker (SW) & 1 \\
\hline & Nutritionist (Nu) & 1 \\
\hline & Sport manager (SM) & 1 \\
\hline 3 & Occupational therapist (OT) & 1 \\
\hline & Physiotherapist (Ph) & 2 \\
\hline 4 & Social worker (SW) & 1 \\
\hline & Nurse (N) & 3 \\
\hline & Diagnostic radiographer (DR) & 1 \\
\hline & Social worker (SW) & 1 \\
\hline
\end{tabular}

Ethical approval was provided by the University and was conducted in accordance to the ethical guidelines for educational research published by the British Educational Research Association [17].

\section{Findings}

\subsection{Overview of the Theme}

'Different but the same' was a major theme that emerged from the data. It articulated the academic development experience and the contribution of the multiprofessional cohort to that experience. The doctoral journey is necessarily an individual one but the cohort setting provided opportunity for the students to study alongside others with a shared purpose and the same ultimate goal. This was highly valued by the students because it created a sense of 'sameness' and brought the benefits that might arise from 'any' cohort experience. However the multiprofessional context and the 'difference' between the students offered three identifiable enhancements to the academic process. These are captured in the three subthemes that are presented below. The subthemes are: 1) finding new worlds 2) getting clear and being clear and 3) travelling alone together.

\subsection{Finding New Worlds}

The students commented on their exposure to new worldviews and research contexts through the rich mix of professions represented in the cohorts. Even for those accustomed to multiprofessional learning, this mix was considerably greater than they had previously experienced. All the students viewed the experience positively and identified the enjoyment and intellectual stimulation that came from hearing about other people's worlds of work. This exposure to new worldsemphasised the differences between them that proved to be intellectually challenging and offered a range of tangible benefits: academic 
stimulation, widening perspectives and discovery of new ways of knowing.

The participants in Focus Group 1 collectively identified how studying alongside those from such a diversity of professional backgrounds, 'people from opposite ends of the scale, with very different ways of thinking and strong viewpoints' had provided benefits beyond their expectation. One described 'the huge amounts' that she had learnt from other disciplines and another 'the breadth of understanding' he had achieved.

This was echoed by discussions in the other Focus Groups that indicated how this exposure meant the students had 'gained an appreciation of lots of different worlds' which had helped them to 'understand our professional lives and how that plays out.' The language they used suggests a journey of discovery; fresh new insights into areas of knowledge and research approaches that they previously did not know existed.

'there's something between all of us that we're interested in ... I can sit here and think, yeah, those connections are firing and at some point there'll be some map somewhere that would, a route map that would actually articulate what each of us is interested in and what those commonalities are.' (Year 1, N)

These discoveries were bounded by the disciplinary concept of Health and Wellbeing that offered a shared identity. This provided a degree of coherence to the discussion. It also offered an opportunity to explore points of connection, which several participants identified as being important in enabling them to develop a congruent, expanded understanding.

'Because someone else will say something and you can put the jig-saw together, because other people are coming from a different perspective but arewanting to know the same affirmation or clarity of a point.' (year1, $N$ )

By being exposed to fellow students articulating their own epistemological stance, 'new worlds' were opened up for the participants and clarified through the 'reasons, rationales and real live examples' that they described. Through these discursive processes, the impenetrable language of theoretical texts were brought to life.

'There's a bit of us that are walking paradigms. So we've kind of got these hats, whether you've got your constructivist hat on or not, do you know what I mean?' (year $1, N$ ).

This apparent embodying of theoretical positions in others enabled the students to begin to differentiate and articulate their own theoretical stance.

'By bringing the characters to life of whatever the philosophy is, it has allowed me to define myself and my philosophical stance much easier' (year 1, M).

This occurred in a context where the diversity of the group ensured that there was no opportunity for 'taken for grantedness'. The students came from very different professional backgrounds that were underpinned by specific educational traditions. In these traditions, specific forms of knowledge may be privileged and in some instances, professional socialisation results in the validity of certain research approaches not being recognised. In the focus group discussions, the participants reflected on these processes and the transformative effect of having these privileged perspectives challenged.

'When I came in, it was all about number crunching and it was about cause and effect and that's just reflective of what I've done traditionally and what I teach and the way I work .... and for me it's been a whole transformative process ...its opened up these new worlds, this qualitative stuff, [I was thinking], its just words, it doesn't mean anything ... and now that's completely flipped'(year 2, Nu)

'Because I looked at it from the other side... my world is always around interpretive and that kind of thing because it has to be. But then I said, actually I wouldn't even know there was a problem without the positivists.' (year 1, SMS)

\subsection{Getting Clear and Being Clear}

Being able to explore and understand the theoretical and epistemological perspectives from which different research approaches emerge is a key component of doctoral study. The discursive process of articulating ideas is more complex in a multiprofessional context where shared understanding is less likely. Being able to explain theoretical ideas in that context demands clarity. As well as offering the benefits that accrued from exposure to a rich diversity of perspectives as discussed above, the multiprofessional composition of the group meant that the students had to clarify their own thinking in order to clearly communicate their ideas to others. This discursive process appeared to be facilitated by the lack of professional hierarchy resulting from the multiprofessional context.

In the discussion in FG 2, the participantcontrastedthis lack of hierarchy with their previous learning experiences where they had felt that 'I'm not going to say anything if they're not going to say anything or 'I'm not going to be the little person who's going to question this in front of everyone else. 'Within the doctoral cohorts, not-knowing was acceptable and it was safe for senior professionals to acknowledge their knowledge deficiencies and seek clarification.

'We're all very different, so it's really easy to go, can I just ask a point to clarify, or I don't understand what you're talking about.' (year $1, N$ ).

'Nobody's ever afraid to say, you know, I'm not getting on with that or I don't understand that. There's no, you don't feel as if you can't vocalise your fears about it. ' year $1 \mathrm{DR})$.

In this environment, which was characterised by curiosity, the students were challenged in a nonthreatening way by their fellow students to fully clarify the methodological approaches they were planning to take for their individual studies. The context within which they were required to 'be clear' was challenging because knowledge could not be taken for granted to the extent that it would be in a uni-professional context. The discursive processes within the cohort created a vehicle through which students were required to clarify personal understanding of their own position by articulating their ideas and theoretical standpoints in terms accessible to a diverse audience. The need to be clear for others enabled them to become clear for themselves and through this to refine their thought processes. This was particularly valuable in the early stages of the journey as the students grappled with new ideas and sought to establish a firm knowledge base from which to develop their doctoral project.

'I think the robustness of my research has been enriched already by the fact that I have been stimulated by 
these characters that have helped me form where I sit' (year 3, Ph)

However, this had variable impact over the course of the doctoral journey. The discursive processes that were initially helpful for students to identify a route for their journey, were less helpful when they had chosen their route and committed to a research approach. At this point, it was important for them to move forward on their chosen path. However, the students' emergent understanding could remain fragile in terms of being able to robustly defend their decisions. Too much peer challenge at this stage could have a disrupting influence on progress because it had the potential to undermine confidence in the theoretical decisions made and therefore their project design.

'You'd got your ideas and you'd think, right, I understand this now and then somebody throws this other spanner in the works. And so it got to the point where, no, you don't want any more spanners, you just want to stick to what you think you know '(year 4, DR)

'We went with ideas and you think, I'm just getting, you're going to get on top of phenomenology, I doubt many people are. But then you think I know where I am, I know where I'm going and then someone says something and you're like NO!!!, you know what I mean?'(year 4, SW)

However, in the later stages, when the students were more established on their doctoral journey and more confident of their chosen theoretical pathway, the discursive processes and the academic challenge became productive again; the insights of peers offered a means through which to improve the final product.

'I think that's been great, when we've presented our research and people say, just something I'd not thought about my research ... and it really was a pivotal thing that I would have got roasted for if I'd not answered that question and I'd not thought of it for myself.'(year 4, SW)

\subsection{Travelling Alone Together}

Although the professional doctorate provides a cohort experience, the nature of doctoral study per se is necessarily individual and remains a lone endeavour. This sub-theme brings together the concepts of 'finding new worlds' and 'getting clear and being clear to illuminate the notion of the students' individual pathways towards a shared goal. The participants identified both motivational and academic benefits of 'travelling alone together.'

The motivational benefits offered by the cohort experience continued over the course of the programme. In the early stages, when the students were becoming acclimatised to the daunting prospect of doctoral study, their confidence was boosted by the fact that they were studying alongside others facing comparable challenges as illustrated in the sub-theme 'finding new worlds.'

As their project ideas developed, the cohort experience provided motivation to continue on their individual journeys through mutual support which included practical assistance. The students were all senior professionals with extensive networks and access to a wide range of resources. There was an overall willingness to share these with their fellow students and assist each other in multiple ways.

'We were all aiming for the same thing, we all want to get our doctorate so people were very keen to share and to assist each other in getting to that goal.' (year 4, N)
The academic benefits of 'travelling alone together' altered over the course of the programme. As discussed previously, the theoretical discussion that had enabled the students to get clear, could undermine theoretical confidence further along the journey. Additionally it became evident that continuing these discussions could also serve as a potential distraction, diverting time from their new priority to move forward with their project.

'I went to a couple [of seminars] but by that point you'd got down to your journey and you needed to just get down to work rather than any more theoretical discussions, I just knew where I was going and what I needed to do. So that sort of thing is good early on but it comes back to once you're down the path of actually doing your project, you just need to do what you need to do.' (year $4, N$ )

However, the participants identified benefits of continued formalised group contact in the later part of the programme. In this later phase, the doctoral journey had become increasingly individual and was characterised by the isolating experience of part-time doctoral study. As the student below describes, meeting with peers was academically stimulating and helped to sustain them through the reality of combining professional practice with doctoral study.

'It's like going up the mountain and its really great when you're there with everybody ... its really stimulating and the conversations we have and our tutor and things, and then it's like back to the real world and it's kind of further away again as you step away and you go back down.' (year3, SW)

At this later stage of the programme, beneficial sharing appeared to be the opportunity to share progress with the cohort and to gain feedback on their work. As well as serving as a motivating force, this regular input improved the quality of their projects and helped them to begin to develop a robust justification for their study in preparation for examination at doctoral level.

'I suppose one of the things that helps things is about what progress you're making with your research, and then people giving you feedback and people will be present from different disciplines' (year 4, N).

\section{Discussion}

The findings from this study suggest ways in which doctoral students in multidisciplinary cohorts are 'different but the same'and how this contributes to their learning experience.

Our findings suggest that these participants found the cohort experience beneficial. The benefits of a cohort experience, in offering social and emotional support, have been identified [18] and the value that it affords incombating the isolating and solitary nature of doctoral study and the negative impact on attrition and completions are well recognised $[19,20]$. The attrition and noncompletion rates in the US have been described as a 'silent epidemic' [18], and a similar pattern is reported in the UK [21]. For those studying part-time, the challenges are greater and this is reflected in the completion rates that are substantially lower than those from full time students [21]. The motivational benefits of travelling together with a shared purpose towards a common goal identified in our study support those reported elsewhere. Ali andKohun 
identify four stages in the doctoral process and outline the challenges associated with them [19]. Stages three and four, which cover defining and conducting the project, have most relevance to this discussion. In relation to stage three, they identify that the uniqueness of the topic is a major isolating factor for students in that they have to prepare themselves alone to meet the requirements of getting their proposal accepted. Our study indicates that the cohort context, and specifically the ongoing discussions that took place within the cohort, supported this process in two ways. Firstly offering opportunity for refining and shaping ideas, and secondly creating a setting in which to rehearse the rationale and justification for those ideas.

Ali and Kohun describe the dissertation phase as stage 4. They remark on the isolation of working alone on writing up and the lack of vital support that could be gained from communicating with other students [19]. Our findings suggest a protective factor against isolation through the students' continued interaction within their cohort and a further effect of instigating and developing extended academic and professional networks between the different cohorts.

The value of this co-operative effect cannot be assured. In some uni-professional doctoral contexts, where students study alongside one another in a cohort setting, competition between students has been reported as detrimental to completion rates [22]. Additionally, in some multiprofessional contexts, professional power agendas have been identified as a barrier to individual learning [23]. These assertions are not supported by the findings of our study. Furthermore, our study indicates specific benefits that have not been previously reported.

The participants were open to the 'new worlds' they were encountering in ways that were characterised by not having to feel defensive about their own positions, and being amenable to having those positions modified. The fact that peers were from a different professional world seemed to enhance the probing of the questions and challenged the taken for grantedness that occurs in any uniprofessional context. This, together with the need to 'get clear and be clear', enhanced the learning experience and indicates the value of a multiprofessional cohort approach to doctoral study.

A number of learning theories have been drawn on to understand learning across multidisciplinary groups [24]. The contact hypothesisis used extensively in interprofessional education [25], where collaboration is a valued outcome. The approach is based on an assumption that eroding negative stereotypes promotes more positive attitudes towards other professions, thus leading to an improvement in collaborative working [26,27,28,29]. This is mediated through establishing a number of learning conditions including: assuming equal status, assuring a cooperative atmosphere, working on common goals, a context of institutional support and awareness of similarities and differences[28,30].

The doctoral programme explored in this study, although strongly multi-professional, is not specifically focussed on interprofessional interests of supporting enhancement in collaborative practice. However, we suggest that the perspectives provided by the contact hypothesis remain useful in considering the benefits of doctoral multiprofessional cohorts where, although collaborative practice may not be a projected outcome, the features ofestablished professionals with a shared commitment towards supporting achievement of their own individual goals are apparent. The positive aspects of the cohort experience the students identified can be traced to the conditions above, although it is not clear how they have emerged. We propose that processes may be operating at an institutional and/or an individual level. At an institutional level, the programme is situated in a University with a strong ethos of interprofessional education that is realised through the prevailing pedagogical approach which tends to facilitate practices that promote the learning conditions proposed by the contact hypothesis. At an individual level, the characteristics of the students echo the conditions required for collaborative working: they are mature professionals for whom difference does not pose a professional threat, in that they have a tolerance of difference, seeing it as an opportunity to learn and clarify their own position. They study within an ethos of co-operativeness, coming together with a common purpose and a shared goal of travelling alone to individual destinations, but together on the route.

This study was confined to a single doctoral programme in one academic institution and the findings were determined by the educational context within which they were generated. Their generalisability to substantially different pedagogical approaches may be limited. Data were collected by members of the programme teaching team which may have influenced responses although any such effect is likely to be limited given the professional seniority of the participants and the topic of enquiry.

\section{Conclusion}

This study demonstrates the ways in which multiprofessional learning benefits those studying at doctoral level and suggests that the contact hypothesis may provide a pedagogical guide to supporting multiprofessional cohorts. The cohort effect appears to be particularly important within the context of doctoral study because it offers protection from the isolation that characterises the student experience at this level. Such protection can make an important contribution to tackling the silent epidemic of non-completion although a more longitudinal approach is required to determine the effect of a multiprofessional cohort experience on attrition.

This study indicatesadditional benefits of studying alongside others in an environment within which contact conditions operate. Enhancing the quality of the educational experience through multiprofessional study offers the potential to make an important contribution to creating a workforce of senior professionals who are better equipped to meet the challenges of providing for the health and wellbeing of society in the $21^{\text {st }}$ century. However, further work is indicated to understand how these challenges are addressed in the subsequent working practices of these leaders and the services they shape.

\section{Acknowledgements}

We acknowledge the contribution of Maria Burton who assisted with data collection and to the doctoral students for sharing their insights and experiences. 


\section{Declaration of Interest}

The authors report no declarations of interest.

\section{References}

[1] Hoddel, S. Professional Doctorates. Litchfield, UK Council for Graduate Education. 2002.

[2] Scott, D., Brown, A., Lunt, I \& Thorne, L. Professional doctorates: Integrating professional and academic knowledge. Maidenhead, Open University Press. 2004.

[3] Brown, K. \& Cook, C. Professional Doctorate Awards in the UK, Litchfield. UK Council for Graduate Education. 2010.

[4] Park, C. Redefining the Doctorate: discussion paper, York, The Higher Education Academy. 2007.

[5] Barr, H. Low, H. Introducing Interprofessional Education. Fareham. Centre for the Advancement of Interprofessional Education, P4. 2013.

[6] World Health Organisation, Framework for Action on Interprofessional Education and Collaborative Practice, Geneva, WHO Press. 2010.

[7] Department of Health,Liberating the NHS: Developing the healthcare workforce - from design to delivery, London, The Department of Health. 2012.

[8] Departmentt of Health, Patients first and foremost: The initial government response to the report of The Mid Staffordshire NHS Foundation Trust public inquiry, London, The Department of Health. 2013.

[9] Department of Health, Delivering high quality, effective, compassionate care: Developing the right people with the right skills and the right values, London, The Department of Health. 2013.

[10] Smith, P., Curtis, H., Sanders, G., Kuit, J.\& Fulton, J."Students' perceptions of the Professional Doctorate". Work Based Learning e-Journal, 2 (1), 135 - 154.2011.

[11] Fulton. J., Kuit, J. \& Sanders, G."The role of the professional doctorate in developing professional practice". Journal of Nursing Management, 20, 130-139. 2011.

[12] Crotty, M. The Foundations of Social Research: Meaning and Perspective in the Research Process, London, Sage. 1998.

[13] Braun, V. \&Clark, V. "Using thematic Analysis in Psychology". Qualitative Research in Psychology, 3. 77-101, p79. 2006.

[14] Fereday, J. \&Muir-Cochrane, E. "Demonstrating Rigor using thematic analysis: a hybrid approach of inductive and deductive coding and theme development". International Journal of qualitative methods, 5 (1), 80-92. 2008.
[15] Patton, M. Qualitative Evaluation and Research Methods ( $2^{\text {nd }}$ ed.) Newbury Park, Sage, 1990.

[16] Hayes, N. "Theory-led Thematic Analysis: social identification in small companies" in Doing Qualitative Analysis in Psychology, Hove, Psychology Press, 93-115. 1997.

[17] BERA Ethical Guidelines for Educational Research, London. British Educational Research Association. 2011.

[18] Jairam, D. \&Kahl, D. "Navigating the doctoral Experience: the role of Social Support in Successful Degree Completion". International Journal of Doctoral Studies, 7, 311-329. 2012.

[19] Ali, A. \& Kohun, F. "Dealing with Isolation Feelings in IS Doctoral Programs". International Journal of Doctoral Studies, 1, 21-33. 2006.

[20] Sikes, P.\& Wellington, J. " 'A doctorate in a tight compartment': why do students choose a professional doctorate and what impact does it have on their personal and professional lives? Studies in Higher Education 31 (6), 723-734. 2006.

[21] HEFCE PhD research degrees: entry and completion, London, Higher Education Funding Council for England Issues Paper, 2-44. 2005.

[22] Anderson, M. S. \& Swazy, J.P."Reflections on the Graduate Student experience: An overview". New Directions for Higher Education, 1, 3-13. 1998.

[23] World Health Organisation, Interprofessional Collaborative Practice in Primary Health Care: Nursing and Midwifery Perspectives Six Case Studies, Geneva, WHO Press. 2013.

[24] Hean, S., Craddock, D.\& O'Halloran, C. "Learning Theories and Interprofessional Education: a user's guide". Learning in health and social care, 8 (4), 250-262. 2009.

[25] Hean, S.\& Dickinson, C. "The contact hypothesis: An exploration of its further potential in interprofessional education". Journal of Interprofessional Care, 19 (5), 480-491. 2005.

[26] Amir, Y. "Contact hypothesis in ethnic relations". Psychological Bulletin, 71, 319-342. 1969.

[27] Rothbart, M.\& John, O. "Social Categorization and behavioural episodes: a cognitive analysis of the effects of intergroup contact". Journal of Social Issues, 41, 81-104. 1985.

[28] Hewstone, M. \& Brown, R. "Contact is not Enough: an Intergroup Perspective on the Contact Hypothesis" in Contact and Conflict in Intergroup Encounters. Oxford, Blackwell. 1986.

[29] Carpenter, J."Doctors and nurses: stereotypes and stereotype change in Interprofessional Education" Journal of Interprofessional Care, 9, 151-161. 1995.

[30] Barnes, D., Carpenter, J. \&Dickinson, C. "Interprofessional education for community mental health: attitudes to community care and professional stereotypes". Social Work Education, 19 (6). 565-583. 2000. 